Vol. 3, No. 1, March 2021 e-ISSN: 2656-4882 p-ISSN: 2656-5935

\title{
Rancang Bangun Aplikasi Pengolalaan Data Atlet IKASI Berbasis Website Menggunakan Framework Laravel
}

\author{
Dita Ferdian Bayu Kusuma ${ }^{1}$, Hendra Marcos$^{2}$, Ika Romadoni Yunita ${ }^{3}$ \\ Program Studi Informatika, Fakultas Ilmu Komputer, Universitas Amikom Purwokerto, \\ Jl. Letjend Pol. Soemarto, Watumas, Purwanegara, Kec. Purwokerto Utara, \\ Kabupaten Banyumas, Jawa Tengah 53127 \\ Email:12deflokusuma@gmail.com, ${ }^{2}$ hendra.marcos@amikompurwokerto.ac.id, \\ 3ikarom@amikompurwokerto.ac.id
}

\begin{abstract}
Ikatan Anggar Seluruh Indonesia atau disingkat IKASI merupakan induk organisasi cabang anggar diseluruh Indonesia. IKASI Purbalingga sekarang ada sekitar 73 anggota dari tahun 2010 sampai sekarang dan selalu bertambah setiap tahunnya. Namun dengan banyaknya anggota tidak diimbangi dengan sistem pencatatan dan pemantauan atlet yang baik. Hal ini membuat IKASI Purbalingga seringkali terhambat dalam pendataan dan melihat perkembangan atlet saat akan digunakan sebagai bahan acuan untuk memilih atlet yang akan diikutkan perlombaan tingkat provinsi, nasional maupun internasional karena masih menggunakan cara manual. Tujuan dari penelitian ini adalah membangun sebuah aplikasi pengolahan data atlet IKASI berbasis website menggunakan framework Laravel. Penelitian ini membahas tentang pembuatan aplikasi pengelolaan data dan cara melihat perkembangan atlet sehingga dapat dipantau dengan baik. Metode pengembangan sistem yang digunakan dalam penelitian ini adalah metode waterfall, dimana proses pembuatannya bertahap hingga diujikan Hasil dari penelitian ini menunjukkan $84,76 \%$ pengguna menyatakan aplikasi ini setuju untuk digunakan memantau perkembangan atlet, agar mudah dalam setiap latihan dan pertandingan.
\end{abstract}

Keywords: Aplikasi, Atlet, IKASI, Laravel, Website

\section{PENDAHULUAN}

Dunia olahraga saat ini berkembang pesat khususnya di Indonesia. Cabang olahraga yang semakin berkembang salah satunya adalah anggar. Anggar di Indonesia berdiri pada tahun 1948 yang diperkenalkan pada Pekan Olahraga Nasional pertama di Solo. Organisasi induk cabang olahraga anggar di Indonesia bernama Ikatan Anggar Seluruh Indonesia (IKASI). IKASI Kabupaten Purbalingga merupakan induk organisasi cabang anggar se-kabupaten yang ada di Jawa Tengah, berdiri pada tahun 2010. Menurut Bapak Anas Saeful Bahtiar S.Pd. selaku ketua dan pelatih, saat ini ada 30 anggota aktif dari 73 anggota. Pada tahun 
2018 ada 13 anggota aktif, dan pada tahun 2019 sampai saat ini bertambah 17 anggota aktif baru.

Pendataan atlet saat ini masih menggunakan cara manual yaitu pada buku catatan pelatih. Calon atlet mengisi formulir yang disediakan saat latihan pertama. Dalam memilih dan melihat perkembangan atlet, pelatih hanya melihat data seleksi bertanding yang ditulis. Setelah itu data tidak disimpan dengan baik, menyebabkan data hilang, rusak, dan dilakukan berulang-ulang sehingga pendataan tidak efektif. Seharusnya dengan pendataan yang baik dapat membuat pembinaan atlet lebih baik [1], namun belum ada ketertiban administrasi, meskipun menurut ketua dan pelatih sendiri akan menerapkan tertib administrasi. Apalagi dengan bertambahnya anggota dan atlet membuat pelatih kesulitan dalam melakukan pendataan jika tidak diimbangi dengan sistem yang baik, hal ini penting dilakukan agar atlet dapat berkembang dengan baik [2]. Masalah ini membuat organisasi memerlukan sistem terkomputerisasi agar pembinaan atlet semakin baik dan teratur [3].

Pada penelitian sebelumnya tentang pendataan perkembangan atlet sudah pernah dilakukan, beberapa hasil pembahasan penelitian sebelumnya antara lain oleh Romdoni [4], dan Afwani [5]. Penelitian tersebut membangun sistem dalam pengelolaan data atlet. Selanjutnya pada penelitian yang dilakukan oleh Harianto [6] membangun sistem pendukung keputusan untuk penentuan atlet berbakat menggunakan fuг:sy, sedangkan Budiarto [7] membangun sistem seleksi atlet berbakat. Beberapa sistem yang sudah dikembangkan tersebut menggunakn subyek penelitian yang sama yaitu atlet. Maka dari itu perlu dibuat sistem berbasis web agar perkembangan atlet mudah dipantau oleh pelatih. Aplikasi berbasis website yang dapat mengelola data dan melihat perkembangan atlet dimana akan memberikan manfaat serta membantu. Dimana aplikasi berbasis website mempunyai keunggulan yaitu dapat diakses oleh pengguna menggunakan web bronser yang terdapat di seluruh sistem operasi komputer desktop maupun smartphone [8].

Pada pembuatan aplikasi berbasis website ini digunakan framework. Laravel untuk mempermudah pembuatan aplikasi, dimana framework ini sederhana [9] dan mempunyai fleksibilitas serta menggunakan versi PHP yang selalu up-to-date, karena mensyaratkan PHP versi 5.3 keatas [9]. Dibandingkan dengan framework lainnya, laravel tergolong baru dan lebih dinamis dibandingakn yang lain [10].

\section{METODE PENELITIAN}

Metode yang digunakan dalam penelitian ini adalah metode waterfall. Waterfall adalah metode pengembangan sistem dimana proses pengembangan sistem dengan menggunakan metodologi dan model yang digunakan orang untuk mengembangkan sistem sebelumnya [11]. 
Sedangkan menurut Susilo [12] waterfall adalah model yang paling banyak digunakan dan merupakan model tradisional atau klasik yang sering disebut model air terjun, dimana model air terjun ini mempunyai alur hidup yang sekuensial atau berurutan dimulai dari analisis, desain, pengkodean, pengujian dan tahap pendukung. Metode ini mempunyai alur hidup perangkat lunak yang urut dari analisis, desain, pengkodean, pengujian, dan tahap pendukung [13]. Adapun ilustrasi metode pengembangan waterfall dapat dilihat pada gambar 1 .

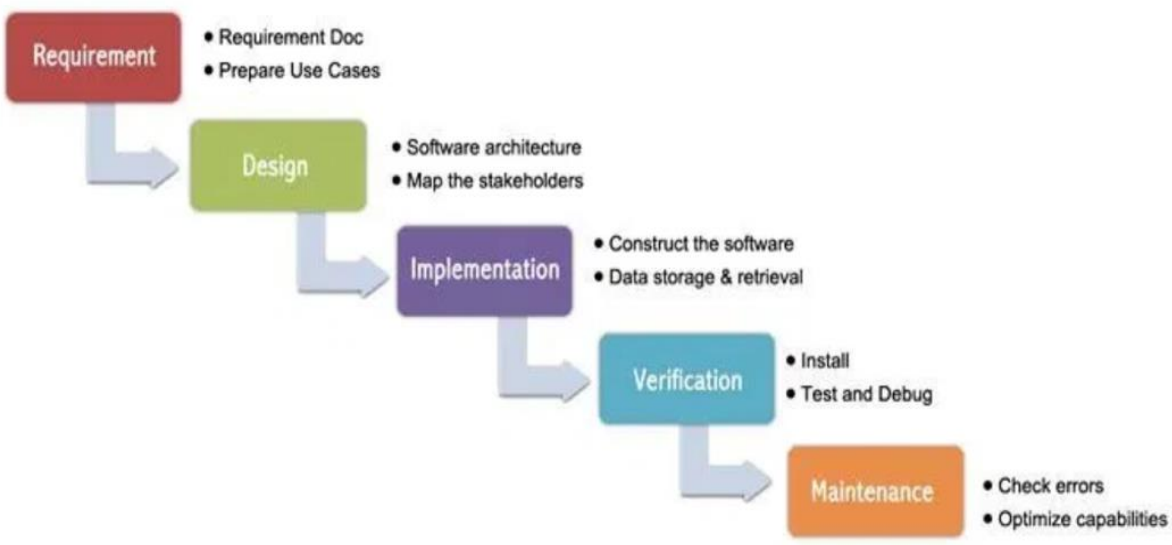

Gambar 1. Waterfall Model [11].

Ilustrasi metode pengembangan waterfall model pada Gambar 1 dapat dijelaskan sebagai berikut:

\section{1. Requirement (Analisis Kebutuhan)}

Requirement adalah proses analisis atau pengumpulan data-data yang berkaitan dengan sistem yang akan dibuat. Pengumpulan data ini bisa dilakukan dengan wawancara, studi literatur, observasi atau penelitian langsung. Informasi ini bisa diperoleh melalui wawancara, diskusi atau survei langsung. Informasi dianalisis untuk mendapatkan data yang dibutuhkan oleh pengguna.

\subsection{Design System (Desain Sistem)}

Proses ini akan berfokus pada pembangunan struktur data, arsitekur perangkat lunak, perancangan interface, perancangan fungsi internal dan eksternal serta detail dari setiap algoritma prosedural. Tahapan design akan menghasilkan dokumen bernama "sofware requirement" yang nantinya menjadi landasan para programmer dalam membuat code-code aplikasi. Perancangan yang dilakukan adalah merancang semua kebutuhan pengguna sesuai dengan perancangan 
diagram konteks, data flow diagram (DFD), entity relationship diagram (ERD), basis data, dan user interface.

\section{3 Implementasi (Pengerjaan)}

Tahap ini adalah tahapan pembuatan aplikasi dengan menggunakan kode-kode bahasa pemrograman PHP. Proses penulisan sinkode (coding) aplikasi mengacu pada dokumen-dokumen yang telah dibuat sebelumnya. Pengkodean ulang dilakukan apabila ditemukan bugs dan dianggap berhasil apabila hasil pengkodean sesuai dengan keinginan dan kebutuhan. Peneliti melakukan pengkodean menggunakan bahasa pemrograman PHP dan database MySQLi serta menggunakan Framework Laravel.

\section{4 Verification (Verifikasi)}

Tahapan verifikasi meliputi pengintegrasian sistem dan juga melakukan testing terhadap aplikasi yang telah dibuat. Sistem akan diverifikasi untuk diuji sejauh mana kelayakannya. Pada penelitian ini sistem pengujian yang digunakan yaitu black box testing dan kuesioner (pengguna). Pengujian black box testing berfokus kepada fungsional interface aplikasi yang sedang dibangun, sedangkan pengujian menggunakan kuesioner dilakukan untuk mengetahui kepuasan pengguna dengan menggunakan skala likert. Skala likert memiliki fungsi untuk mengukur sikap persepsi dan pendapat seseorang tentang fenomena sosial [8]. Pengujian ini dilakukan untuk mengetahui aplikasi yang dibangun sudah sesuai dengan keinginan dan kebutuhan.

\section{4 Maintenance (Pemeliharaan)}

Tahapan ini umumnya meliputi tahapan penginstalasian perangkat lunak dan pengujian aplikasi. Maintenance juga adalah bentuk tanggung jawab pengembang untuk memastikan aplikasi dapat berjalan lancar setelah diserah-terima kan pada klien dalam periode waktu tertentu.

\section{HASIL DAN PEMBAHASAN}

\subsection{Analisis Kebutuhan}

Pada tahap ini peneliti melakukan analisis kebutuhan untuk membangun aplikasi. Kebutuhan fungsional dan non fungsional diperlukan untuk langkah awal dalam pengembangan aplikasi. Kebutuhan fungsional yang berkaitan dengan aplikasi secara langsung yaitu, masukan user/pengguna aplikasi (admin, pelatih, dan atlet) kebutuhan proses, dan kebutuhan keluaran (output yang dihasilkan). Kemudian kebutuhan non fungsional berkaitan dengan alat dan bahan yang diperlukan dalam proses pembuatan aplikasi. 
Vol. 3, No. 1, March 2021

p-ISSN: 2656-5935 http://journal-isi.org/index.php/isi

e-ISSN: 2656-4882

\subsection{Desain}

Perancangan aplikasi pengelola data dan statistik atlet anggar terdiri dari diagram konteks, data flow diagram, entity relationship diagram, perancangan basis data dan user interface.

\subsubsection{Diagram Konteks}

Diagram konteks digunakan untuk menggambarkan hubungan antara entitasentitas yang terdapat diluar sistem dan masukan serta keluaran sistem. Pada Gambar 2 menjelaskan bagaimana proses yang terjadi pada aplikasi pengelola data dan statistik atlet anggar.

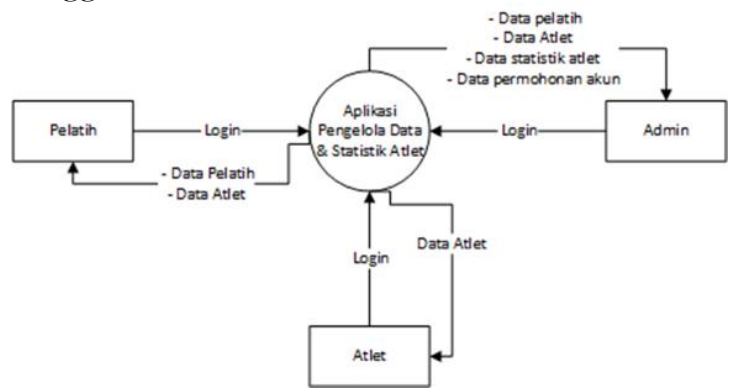

Gambar 2. Diagram Konteks

\subsubsection{Data Flow Diagram}

Data flow diagram (DFD) digunakan untuk menggambarkan suatu aliran informasi yang diaplikasikan saat data bergerak dari input menjadi output. Gambar 3 menunjukkan DFD level 0 yang menggambarkan seluruh proses aplikasi pengelola data dan statistik atlet anggar.

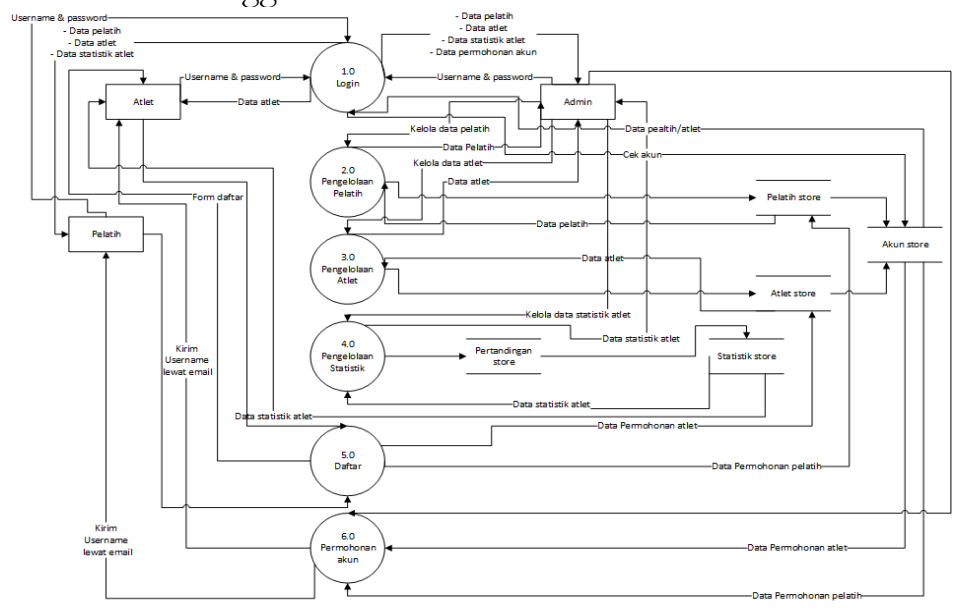

Gambar 3. Data Flow Diagram 
Vol. 3, No. 1, March 2021

p-ISSN: 2656-5935 http://journal-isi.org/index.php/isi $\quad$ e-ISSN: 2656-4882

\subsubsection{Entity Relationship Diagram}

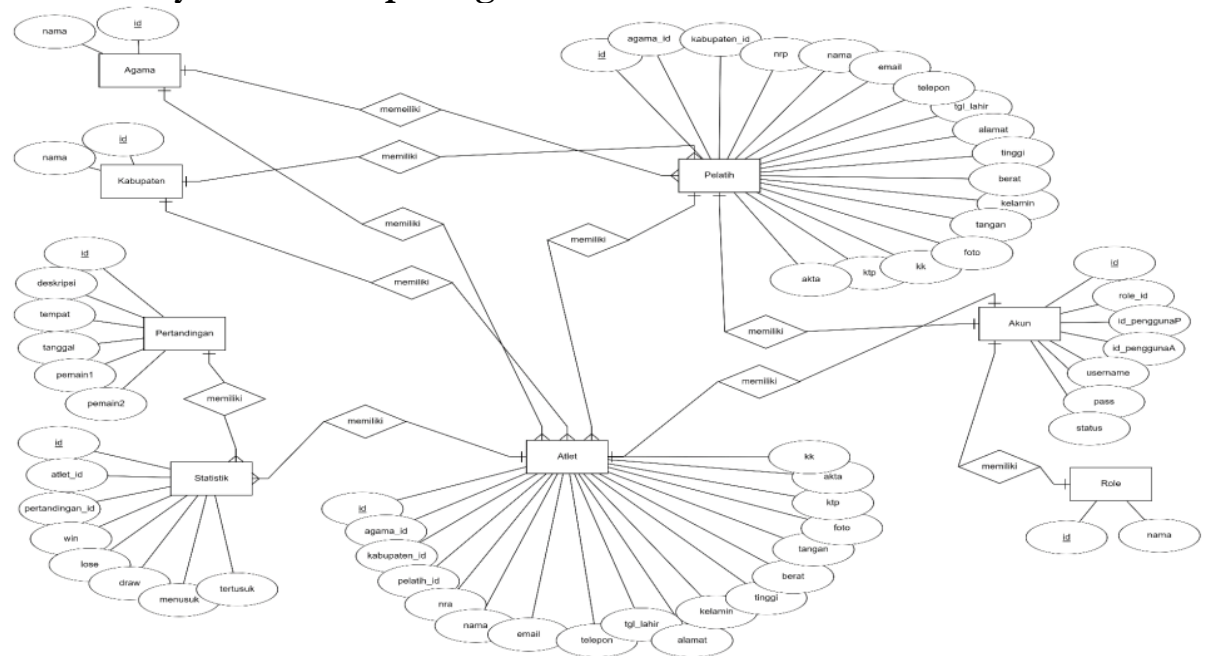

Gambar 4. Entity Relationship Diagram

\subsubsection{Perancangan Basis Data}

Adapun struktur tabel yang digunakan dalam perancangan aplikasi pengelola data dan statistik atlet anggar yang dapat dijelaskan melalui tabel sebagai berikut:

Tabel 1. Basis data "pelatih"

\begin{tabular}{cccc}
\hline Field & Type & Size & Keterangan \\
\hline id & bigint & 20 & Primary key \\
kabupaten_id & bigint & 20 & Foreigen key \\
agama_id & bigint & 20 & Foreigen key \\
nrp & varchar & 9 & \\
email & varchar & 255 & \\
nama & varchar & 255 & \\
telepon & varchar & 255 & \\
tgl_lahir & date & & \\
alamat & text & & \\
kelamin & enum('L','P') & & \\
tinggi & varchar & 255 & \\
berat & varchar & 255 & \\
tangan & enum('Kanan','Kiri') & & \\
ktp & text & & \\
akta & text & & \\
kk & text & & \\
foto & text &
\end{tabular}


Vol. 3, No. 1, March 2021

p-ISSN: 2656-5935 http://journal-isi.org/index.php/isi e-ISSN: 2656-4882

Tabel 2. Basis data "Atlet"

\begin{tabular}{cccc}
\hline Field & Type & Size & Keterangan \\
\hline id & bigint & 20 & Primary key \\
kabupaten_id & bigint & 20 & Foreigen key \\
agama_id & bigint & 20 & Foreigen key \\
pelatih_id & bigint & 20 & Foreigen key \\
nra & varchar & 9 & nra \\
email & varchar & 255 & email \\
nama & varchar & 255 & nama \\
telepon & varchar & 255 & telepon \\
tgl_lahir & date & & tgl_lahir \\
alamat & text & & alamat \\
kelamin & enum('L','P') & & kelamin \\
tinggi & varchar & 255 & tinggi \\
berat & varchar & 255 & berat \\
tangan & enum('Kanan','Kiri') & & tangan \\
ktp & text & & ktp \\
akta & text & & akta \\
kk & text & & kk \\
foto & text & & foto \\
\hline
\end{tabular}

Tabel 3. Basis data "Akun"

\begin{tabular}{cccc}
\hline Field & Type & Size & Keterangan \\
\hline id & bigint & 20 & Primary key \\
username & varchar & 255 & \\
pass & varchar & 255 & \\
status & enum('terima','tidak') & & \\
role_id & bigint & 20 & foreign key \\
id_penggunaP & bigint & 20 & foreign key \\
id_penggunaA & bigint & 20 & foreign key \\
\hline
\end{tabular}

Tabel 4. Basis data "Pertandingan"

\begin{tabular}{cccc}
\hline Field & Type & Size & Keterangan \\
\hline id & bigint & 20 & Primary key \\
deskripsi & text & 255 & \\
tempat & text & & \\
tanggal & date & & \\
pemain1 & bigint & 20 & \\
pemain2 & bigint & 20 & \\
\hline
\end{tabular}




\section{Journal of Information Systems and Informatics}

Vol. 3, No. 1, March 2021

p-ISSN: 2656-5935 http://journal-isi.org/index.php/isi e-ISSN: 2656-4882

Tabel 5. Basis data "Statistik"

\begin{tabular}{cccc}
\hline Field & Type & Size & Keterangan \\
\hline id & bigint & 20 & Primary key \\
atlet_id & bigint & 20 & Foreign key \\
pertandingan_id & bigint & 20 & Foreign key \\
win & varchar & 255 & \\
lose & varchar & 255 & \\
draw & varchar & 255 & \\
menusuk & varchar & 255 & \\
tertusuk & varchar & 255 & \\
\hline
\end{tabular}

\subsubsection{User Interface}

User interface dibuat untuk menggambarkan gambaran sebenarnya dari aplikasi yang akan di bangun.
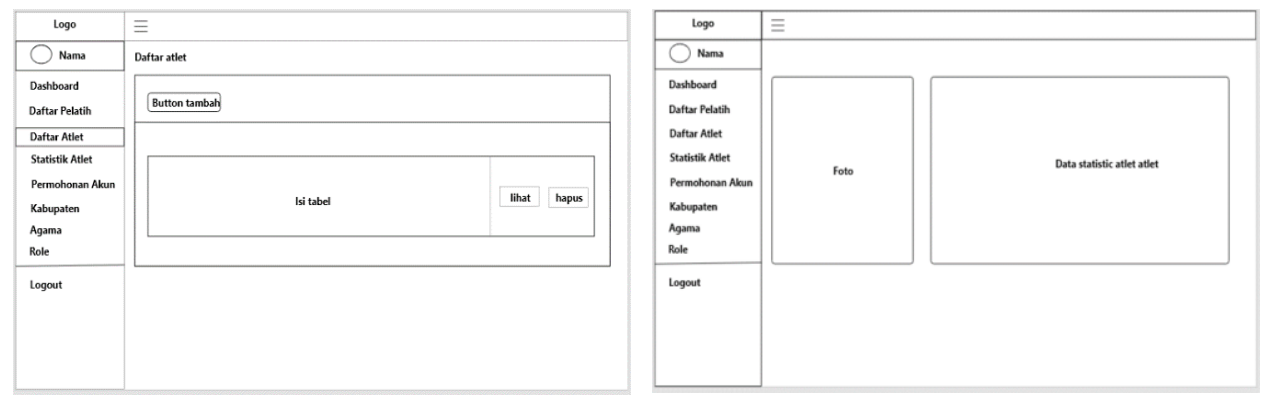

Gambar 5. User interface data atlet

\subsection{Pengerjaan}

Tahap pengerjaan memerlukan kode program menggunakan framework Laravel. Tujuan dibuat menggunakan laravel adalah untuk mempermudah pengkodingan dalam membuat sebuah aplikasi berbasis website. Framework ini berbasis model view controller (MVC), dimana konsep ini memisahkan antara model, tampilan (view), dan proses menjadi terpisah dan tersusun. Gambar 6 menunjukkan tampilan aplikasi disisi admin. Admin melakukan pengelolaan data atlet untuk pemantauan dan administrasi atlet ketika mau melakukan pertandingan. Pelatih mendapatkan laporan dari sistem dan tidak perlu lagi mencatat dibuku. 
Vol. 3, No. 1, March 2021

p-ISSN: 2656-5935 http://journal-isi.org/index.php/isi e-ISSN: 2656-4882

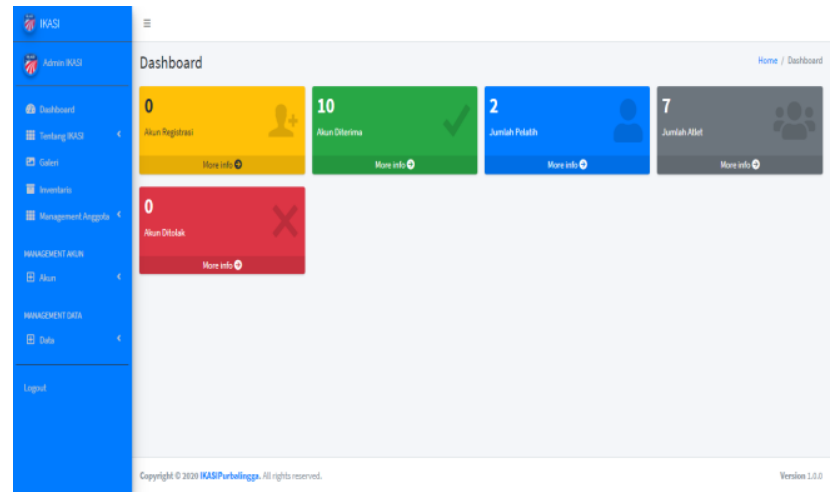

Gambar 6. Tampilan aplikasi

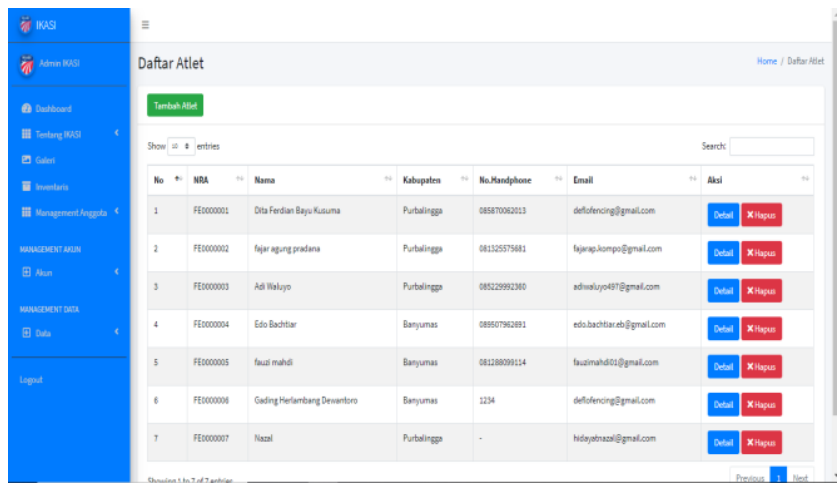

Gambar 7. Tampilan aplikasi pada daftar atlet

Pada Gambar 7 diperlihatkan daftar atlet dan data-data masing-masing atlet. Pelatih dapat memantau perkembangan atletnya. Pada gambar 8 diperlihatkan tampilan perkembangan atlet yang dapat memudahkan pelatih maupun KONI mendapatkan data-data pertandingan atlet.

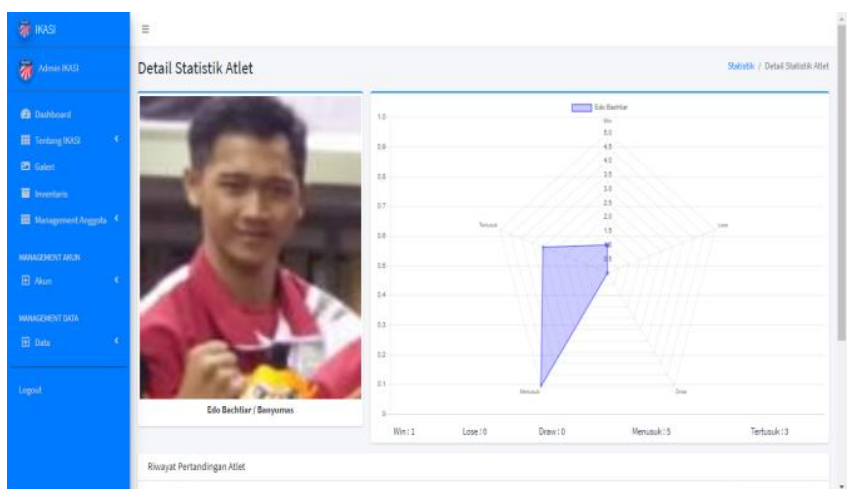

Gambar 8. Tampilan aplikasi pada detail perkembangan atlet 


\subsection{Verifikasi (pengujian)}

Pada tahap ini, verifikasi/pengujian dilakukan menggunakan metode black box testing. Black box testing merupakan salah satu cara dalam menguji sistem atau aplikasi dengan pengujian pada fungsional interface aplikasi yang sedang dibangun [5]. Pengujian juga dilakukan dengan menggunakan kuesioner kepada ketua, pelatih, dan atlet IKASI mengenai kepuasan pengguna. Pengujian ini dilakukan untuk mengetahui apakah aplikasi pengelolaan data atlet anggar berbasis website ini layak digunakan dan dapat memenuhi kebutuhan dalam mengelola data serta melihat perkembangan atlet. Pada Tabel 6 terdapat pertanyaan yang akan diajukan kepada ketua, pelatih, dan atlet.

Tabel 6. Pertanyaan Kuesioner

\begin{tabular}{ll}
\hline No. & \multicolumn{1}{c}{ Pertanyaan } \\
\hline 1. & $\begin{array}{l}\text { Apakah anda setuju bahwa aplikasi yang dibuat ini berguna } \\
\text { untuk pengguna dan IKASI Kabupaten Purbalingga? }\end{array}$ \\
2. & $\begin{array}{l}\text { Apakah anda setuju bahwa aplikasi ini membantu dalam } \\
\text { pengelolaan data atlet IKASI Kabupaten Purbalingga? }\end{array}$ \\
3. $\quad$ Apakah anda setuju bahwa aplikasi ini membantu dalam melihat \\
statistik atlet IKASI Kabupaten Purbalingga? \\
4. $\quad \begin{array}{l}\text { Apakah anda setuju aplikasi ini menghasilkan informasi yang } \\
\text { akurat? }\end{array}$ \\
5. Apakah anda setuju aplikasi ini mudah digunakan?
\end{tabular}

Tabel 7. Bobot Nilai

\begin{tabular}{cc}
\hline Skala Jawaban & Bobot Nilai \\
\hline Sangat Setuju (SS) & 5 \\
Setuju (S) & 4 \\
Cukup (C) & 3 \\
Tidak Setuju (TS) & 2 \\
Sangat Tidak Setuju (STS) & 1 \\
\hline
\end{tabular}

Tabel 8. Bobot Nilai

\begin{tabular}{cc}
\hline Skala Jawaban & Kriteria Hasil \\
\hline Sangat Setuju (SS) & $81 \%-100 \%$ \\
Setuju (S) & $61 \%-80 \%$ \\
Cukup (C) & $41 \%-60 \%$ \\
Tidak Setuju (TS) & $21 \%-40 \%$ \\
Sangat Tidak Setuju (STS) & $0 \%-20 \%$ \\
\hline
\end{tabular}


Kuesioner diberikan kepada ketua, pelatih, dan atlet setelah menggunakan aplikasi ini. Sebagai sampel diambil 30 orang berdasarkan rules of thumb [14]. Kesimpulan hasil persentase skala penilaian 1 sampai 5, dapat disimpulkan bahwa aplikasi pengelola data dan statistik atlet anggar sudah sesuai dengan apa yang diharapkan dengan kriteria skor lebih dari $80 \%$ dan mempunyai rata-rata persentase $84,1 \%$, yang menunjukan aplikasi sangat disetujui oleh pengguna aplikasi dan layak untuk digunakan. Dalam perhitungan kuesioner, peneliti menggunakan skala likert dengan rumus index \% yang membagi total skor dengan hasil perkalian dari skor tertinggi likert, kemudian hasil pembagian tersebut dikalikan dengan 100 [15]. Hasil dari kuesioner tersebut, dapat dilihat pada Tabel 9.

Tabe1 9. Rumus Kuesioner

\begin{tabular}{ccc}
\hline Skala Jawaban. & T $\times$ Pn & Hasil \\
\hline STS & $0 \times 1$ & 0 \\
TS & $2 \times 2$ & 4 \\
C & $7 \times 3$ & 21 \\
S & $79 \times 4$ & 316 \\
SS & $42 \times 5$ & 210 \\
\hline
\end{tabular}

Keterangan:

$\mathrm{T}=$ Total Jumlah responden yang memilih

Pn $=$ Skor skala likert

Menghitung skor ideal tertinggi (Y) dan terendah (X):

$\mathrm{X}=$ Skor terendah likert $\mathrm{x}$ Jumlah responden

$\mathrm{X}=1 \mathrm{x} 130$

$\mathrm{X}=130$

$\mathrm{Y}=$ Skor tertinggi likert $\mathrm{x}$ Jumlah responden

$\mathrm{Y}=5 \times 130$

$\mathrm{Y}=650$

Penyelesaian akhir:

Total Skor $=0+4+21+316+210$

$$
=551
$$

Rumus $\quad=($ Total Skor $/ \mathrm{Y}) \times 100 \%$

$=(551 / 650) \times 100 \%$

$=84,76 \%$

Dari hasil perhitungan kuesioner, didapatkan persentase dengan nilai sebesar 84,76 $\%$. Dari nilai tersebut dapat disimpulkan bahwa aplikasi pengelola data dan statistik atlet baik dan sudah layak digunakan.

\section{KESIMPULAN}


Berdasarkan hasil dari penelitian yang telah dilakukan di IKASI mendapatkan kesimpulan sebagai berikut:

1. Penelitian ini berhasil membuat aplikasi pengelola data dan statistik atlet anggar berbasis website menggunakan framework laravel.

2. Pengujian black box testing fitur yang ada pada aplikasi pengelola data atlet sudah berjalan dengan baik. Berdasarkan hasil kuesioner dengan perhitungan menggunakan skala likert dengan rata-rata persentase 84,1\% dan persentase index nilai sebesar $84,76 \%$, dapat disimpulkan aplikasi baik dan sudah layak untuk digunakan.

Saran yang peneliti berikan untuk pengembangan penelitian selanjutnya yaitu aplikasi dapat dikembangkan dalam versi aplikasi mobile dan dapat dikembangkan lagi untuk tingkat provinsi, nasional, maupun internasional, serta menerapkan notifikasi menggunakan sms gateway atau push notification aplikasi mobile.

\section{DAFTAR PUSTAKA}

[1] B. Nugraha, "Athlete Management Information System in KONI Karawang District," Systematics, vol. 2, no. 2, pp. 86-97, 2020, doi: 10.35706/sys.v2i2.3874.

[2] S. Abhimasta and O. Wiriawan, "Perbandingan Hasil Tes Kondisi Fisik Atlit Anggar Tahun 2018 Dan 2019 Koni Sidoarjo," J. Prestasi Olabraga, vol. 3, no. 3, 2020.

[3] C. Kusumah and T. F. Prasetyo, "Sistem Pendukung Keputusan Mahasiswa Berprestasi Menggunakan Metode Analytical Hierarchy Process ( Ahp ) ( Studi Kasus : Universitas Majalengka )," J. J-Ensitec, vol. 02, no. 01, pp. 4653, 2015.

[4] M. Y. Romdoni and I. Y. Ruhiawati, "Sistem Informasi Data Atlet Pada KONI Provinsi Banten,” J. Innov. Futur. Technol., vol. 2, no. 1, pp. 81-94, 2020.

[5] R. Afwani, S. E. Anjarwani, and B. A. Tauhida, "Rancang Bangun Aplikasi Hybrid Pengolahan Data Anggota dan Event Pada Cabang Olahraga (Cabor) Taekwondo Kota Mataram," J. Teknol. Informasi, Komputer, dan Apl. (JTIKA), vol. 1, no. 1, pp. 111-120, 2019, doi: 10.29303/jtika.v1i1.12.

[6] R. W. Ponti Harianto, "Sistem Pendukung Keputusan Penentuan Atlet Berbakat Menggunakan Metode Fuzzy Mamdani," Bimipa, vol. 25, no. 3, pp. 233-241, 2019.

[7] T. D. Budiarto, "Rancangan Aplikasi Seleksi Atlet Taekwondo Menggunakan Framework Codeigniter Dengan Metode TOPSIS," J. Ris. Komput., vol. 6, no. 3, pp. 227-232, 2019. 
[8] R. Herawan, A. Hidayat, and V. G. Utomo, "Sistem Informasi Penjadwalan Kegiatan Belajar Mengajar Berbasis Web (Studi Kasus: Yayasan Ganesha Operation Semarang) Rudi," Evolusi J. Sains dan Manaj., vol. 4, no. 1, pp. 72 79, 2016.

[9] F. Luthfi, "Penggunaan Framework Laravel Dalam Rancang Bangun," J. Inform. Sunan Kalijaga, vol. 2, no. 1, pp. 34-41, 2017.

[10] S. Susanti, E. Junianto, and R. Rachman, "Implementasi Framework Laravel Pada Aplikasi Pengolah Nilai Akademik Berbasis Web," J. Inform. UBSI, vol. 4, no. 1, 2017, doi: 10.31311/JI.V4I1.1562.

[11] R. S. Pressman and B. R. Maxim, Software Engineering: A Practitioner's Approach. McGraw-Hill Education, 2015.

[12] M. Susilo, R. Kurniati, and Kasmawi, "Rancang Bangun Website Toko Online Menggunakan Metode Waterfall," J. Nas. Inform. dan Teknol. Jaraingan, vol. 2, no. 2, pp. 98-105, 2018.

[13] W. W. Widiyanto, "Analisa Metodologi Pengembangan Sistem Dengan Perbandingan Model Perangkat Lunak Sistem Informasi Kepegawaian Menggunakan Waterfall Development Model, Model Prototype, Dan Model Rapid Application Development (Rad)," J. Inf. Politek. Indonusa Surakarta ISSN, vol. 4, no. 1, pp. 34-40, 2018.

[14] R. A. Sagita and H. Sugiarto, "Penerapan Metode Waterfall Pada Sistem Informasi Penjualan Furniture Berbasis Web," Indones. J. Netw. Secur, vol. 5, no. 4, p. 13, 2016.

[15] U. Raharja, E. P. Harahap, and R. E. Cipta Devi, "Pengaruh Pelayanan dan Fasilitas pada Raharja Internet Cafe Terhadap Kegiatan Perkuliahan Pada Perguruan Tinggi," J. Teknoinfo, vol. 12, no. 2, p. 60, 2018, doi: 10.33365/jti.v12i2.54. 